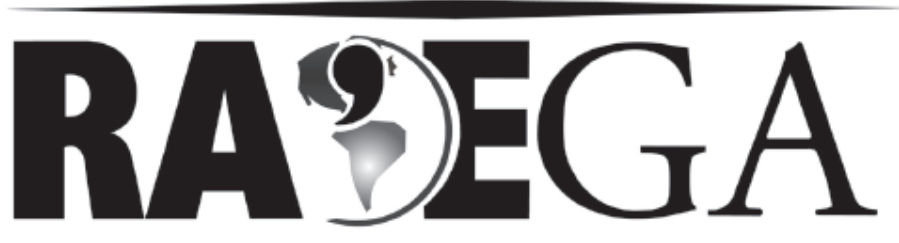

O ESPAÇO GEOGRÁFICO EM ANÁLISE

\title{
PROFESSORES E PARÂMETROS CURRICULARES NACIONAIS (PCN): COMO ESTÁ ESSA RELAÇÃO?
}

\author{
TEACHERS AND THE NATIONAL CURRICULAR \\ PARAMETERS (PCN): WHAT SORT OF CONNECTION IS \\ IT?
}

Flaviana Gasparotti Nunes ${ }^{1}$

\begin{abstract}
RESUMO
Os Parâmetros Curriculares Nacionais (PCN) para o Ensino Fundamental foram introduzidos em 1998 no interior de um conjunto maior de reformas educacionais implantadas pelo Estado brasileiro. No âmbito da Geografia, ocorreram intensos debates sobre as proposições contidas nesse documento no tocante às falhas e lacunas do ponto de vista teórico, metodológico e mesmo didático-pedagógico. Alguns autores posicionaram-se destacando o caráter autoritário e centralizador dos parâmetros, outros apoiaram a proposta argumentando a favor da necessidade de uma orientação curricular nacional. Apesar disso, os PCN constituíram-se num referencial para o ensino de Geografia no Brasil subsidiando planejamentos escolares e sistemas de avaliação. Sendo assim, verifica-se a necessidade de uma reflexão sobre a efetiva relação dos professores com os PCN, ou seja, das conseqüências dos PCN nas práticas de ensino escolares. Neste texto, procuramos trabalhar algumas questões que possam contribuir nessa direção.
\end{abstract}

Palavras-chave: Geografia; ensino; propostas curriculares; PCN; professor.

\section{ABSTRACT}

The National Curricular Parameters (PCN) for primary school were introduced in 1998 within other deep educational changes promoted by the Brazilian State. In the field of Geography there have been heated discussions about the propositions put in this document as far as failures and gaps from a theoretical, methodological and didactical-pedagogical points of view are concerned. While

\footnotetext{
${ }^{1}$ Doutora em Geografia pela UNESP/Campus de Presidente Prudente. Profa. Adjunta da Universidade Federal da Grande Dourados (UFGD). E-mail: flaviananunes@ufgd.edu.br
} 
some authors argue about its authoritarian character, others support its propositons stating that there is the need for a national curricular orientation. However, the PCN are now a reference for the teaching of Geography in Brazil subsidizing school plannings and assessment system. Hence, the need for a reflection on the effective connetion between teachers and the $P C N$ is verified, i.e., the PCN consequences in the school teaching practice must be taken into consideration. In this text, we intend to work on some questions which might contribute to that.

Key words: Geography; teaching, curricular propositions; PCN; teacher.

\section{Introdução}

Os Parâmetros Curriculares Nacionais (PCN) para 0 Ensino Fundamental foram introduzidos em 1998 no interior de um conjunto maior de reformas educacionais implantadas pelo Estado brasileiro.

No âmbito da Geografia, ocorreram intensos debates sobre as proposições contidas nesse documento no tocante às falhas e lacunas do ponto de vista teórico, metodológico e mesmo didático-pedagógico. Alguns autores posicionaram-se destacando o caráter autoritário e centralizador dos parâmetros, outros apoiaram a proposta argumentando a favor da necessidade de uma orientação curricular nacional.

Apesar das críticas, percebemos que os PCN têm sido apontados como referência para a elaboração de planejamentos nas escolas e mesmo para realização de avaliações do sistema escolar.

Diante disso, consideramos importante a reflexão sobre os desdobramentos ou conseqüências dos $\mathrm{PCN}$ em relação às práticas da Geografia escolar. Neste caso, procuraremos, na seqüência, levantar algumas questões para pensarmos como tem sido a relação dos professores com esse referencial curricular.

O texto foi organizado em três partes. Na primeira procuramos situar os PCN no contexto da política educacional em que foram elaborados e implantados. Nesta parte também sistematizamos e pontuamos as principais críticas e problemas apontados em relação ao documento. Na segunda parte, com base em dados e constatações de pesquisas já realizadas, levantamos 
algumas questões sobre a relação dos professores do Ensino Fundamental com os PCN. Na terceira parte refletimos sobre a importância de uma proposta curricular, apontando suas funções no processo de ensino-aprendizagem, bem como elementos que possam conduzir a um estreitamento de relações destas com os professores.

\section{O debate em torno dos PCN}

A introdução dos PCN deve ser considerada no bojo de um conjunto maior de reformas sociais, políticas, econômicas e educacionais que foram implantadas no Brasil principalmente a partir dos anos 1990.

As reformas educacionais e neste quadro os PCN devem ser entendidas no contexto das reformas do Estado brasileiro que “(...) visam delimitar as novas funções e práticas que o Estado, em seu conjunto, e a sociedade, em sua diversidade, deveriam assumir e aprimorar para serem elementos competitivos e eficientes no jogo de forças da concorrência capitalista." (FERRAZ, 2002, p. 208)

É sabido que a necessidade de aprimoramento das funções e práticas do Estado no sentido da competitividade e eficiência, tal como apontou Ferraz é conseqüência de um conjunto de mudanças ocorridas na esfera econômica a partir dos anos 1970. Tais mudanças advindas da chamada crise do fordismo conduziram a uma reestruturação do capitalismo em escala mundial e que dizia respeito não somente a esfera econômica, mas também ao funcionamento da sociedade e seus diversos mecanismos de regulação.

Assim,

Para a efetivação dessa nova forma de gerenciamento da economia capitalista, não se podia permitir que os Estados adotassem medidas autônomas de decisão, pois a economia encontra-se num tal grau de integração que deve ser orquestrada via uma perspectiva global e não local, daí o papel que cabe aos Estados, principalmente os da periferia do sistema, pois aumenta a dependência em relação aos interesses que estão fora de sua autonomia territorial, além de serem entendidos como estruturas que também competem economicamente nesse mercado internacional (...) Tendo isso como pressuposto, os Estados devem sofrer uma profunda reforma, reduzindo seus gastos e custos, ao mesmo tempo em que se facilitam as condições de exploração e acumulação capitalista, permitindo que as empresas atuem em todas as esferas de potencial de 
lucratividade. Nesse contexto é que entendemos as atuais reformas que permeiam ao Estado brasileiro (...). (FERRAZ, 2002, p. 212)

A partir da citação acima destacada, percebemos a relação existente entre a imposição de reformas no âmbito do Estado e as características do atual modelo de economia capitalista. Tal modelo coloca o Estado sob as regras do mercado, devendo o mesmo adequar-se a este.

O conjunto de medidas tomadas para atender a essas regras de mercado ficou conhecido sob a denominação de neoliberais ou neoliberalizantes, em referência à ideologia neoliberal que em linhas gerais, estabelece a busca do Estado mínimo e da soberania da lógica do mercado, tendo em vista que o capital necessitava, naquele momento, estruturalmente de sua globalização e não da interferência do Estado nos moldes do fordismo (o Welfare State ${ }^{2}$ ).

Silva Junior e Sguissardi (1997, p. 36) identificam e acentuam esta relação exemplificando com o caso da educação superior. Os autores afirmam que:

O novo estágio de desenvolvimento do capitalismo mundial e a inserção brasileira neste contexto estão impondo novo espaço social e exigindo novos padrões e hábitos de toda população. Importa, pois, compreender a reforma da educação superior como modernização de instituições sociais em geral e da instituição de educação superior em particular, como controle social para a produção de uma nova subjetividade, conforme teoriza Popkewitz. (...)

A reforma da educação superior faz parte, portanto, de um processo mais amplo e profundo de modernização das instituições sociais com o objetivo de assegurar a hegemonia capitalista a partir de valores produzidos nesta nova etapa deste modo de produção.

A produção de uma nova subjetividade apontada pelos autores diz respeito, principalmente, no caso da educação, à conversão da educação em mercadoria, ao invés de direito social. Nas palavras de Leher (2004) “(...) o prérequisito é converter, no plano do imaginário social, a educação da esfera do direito, para a esfera do mercado, por isso o uso de um léxico empresarial:

\footnotetext{
${ }^{2}$ Para mais detalhes sobre a emergência do neoliberalismo ver: ANDERSON, Perry. Balanço do neoliberalismo. In: SADER, Emir e GENTILI, Pablo (Orgs.) Pós-neoliberalismo - as políticas sociais e o Estado democrático. Rio de Janeiro: Paz e Terra, 1995.
} 
excelência, eficiência, gestão por objetivos, clientes e usuários, empreendedorismo, produtividade, profissionalização por competências, etc."3

No campo educacional, as mudanças requeridas pelo novo projeto societário consubstanciaram-se numa série de medidas, via de regra, impostas pelo Estado em forma de propostas e ações.

Sem dúvida, a Lei de Diretrizes e Bases da Educação (LDB 9.394/96) já apontava ou delineava, desde a discussão para sua formulação, algumas das proposições e políticas colocadas em prática nos últimos anos.

O conjunto de medidas e propostas incluíram desde os Parâmetros Curriculares Nacionais (PCN) para o Ensino Fundamental e Médio, as Diretrizes Curriculares para o Ensino Superior, além do Sistema Nacional de Avaliação expresso pelo Exame Nacional do Ensino Médio (ENEM), da avaliação do ensino superior (antigo "provão" atual ENADE), a avaliação da pós-graduação e os próprios Planos Nacionais de Avaliação dos Livros Didáticos (PNLD).

Neste sentido, conforme afirma Pontuschka (1999, p. 14):

Os PCN's, portanto, não constituem um projeto isolado, mas fazem parte de políticas públicas educacionais iniciadas com a LDB/96 e estabelecidas de acordo com as determinações de políticas mais amplas ditadas pelo conjunto dos países centrais para os países chamados de "emergentes", como o Brasil, sob o respaldo e a cooperação do Estado, e que afetam profundamente o trabalho pedagógico das escolas brasileiras.

É neste contexto, portanto, que os PCN são introduzidos na educação brasileira. No caso específico dos PCN de Geografia para o Ensino Fundamental, foram várias as críticas apresentadas.

A principal delas diz respeito ao caráter autoritário e centralizador da proposta, na medida em que, em seu processo de elaboração houve pouco debate e participação dos professores do Ensino Fundamental, os principais agentes do processo educacional. A partir do processo de elaboração ficou implícita uma concepção de professor como mero executor de tarefas, incapaz de formular propostas de ensino.

\footnotetext{
${ }^{3}$ Nesta mesma direção, Gentili (2000) faz uma interessante e profunda reflexão sobre a nova ordem cultural imposta pelo neoliberalismo que pretende negar ou mesmo dissolver a existência do direito à educação.
} 
Para Sposito (1999, p. 27-28), além disso, não foram consideradas propostas curriculares já existentes e que possuíam avanços do ponto de vista teórico-metodológico e didático.

No entanto, a autora ressalta como pontos positivos do documento a definição de uma filosofia geral do projeto, a valorização da transversalidade e de diferentes linguagens, além da consideração de novos paradigmas teóricometodológicos.

No âmbito da Geografia, uma das questões mais polêmicas trazidas pelos PCN diz respeito à concepção teórico-metodológica implícita no documento. Para Sposito (1999, p. 31), ao invés de uma pluralidade teóricometodológica pretendida pelos autores do texto, fica evidente uma indefinição que se aproximaria mais de um ecletismo.

Oliveira (1999) centra sua reflexão na questão da definição ou indefinição da matriz filosófica do texto dos PCN. Para o autor, o texto "mistura" humanismo com viés historicista clássico, temas relacionados ao positivismo clássico e marxismo conduzindo a um ecletismo que caminha na direção de uma postura fenomenológica.

Neste sentido afirma que:

(...) Aqui por certo está, consciente ou inconscientemente, o real objetivo da concepção baseada no subjetivismo na geografia. Formar cidadãos que apenas se enxerguem como indivíduos, não conseguindo, portanto, enxergarem-se como classe.

Assim, a visão de sociedade expressa nesta concepção passa a ser de uma reunião de indivíduos, e não a união contraditória de classes sociais em luta. (...) (Oliveira, 1999, p. 54)

Em linhas gerais, Oliveira vê inúmeros problemas nos PCN, desde o ecletismo ou indefinição da matriz filosófica até a questão da imposição curricular que acarreta numa única maneira de pensar e fazer Geografia sendo conteudista e individualista.

Sobre os posicionamentos dos geógrafos quanto aos PCN, Zanatta (2005) afirma que:

(...) é bastante diversificado, variando desde o apoio até a negação total de sua legitimidade. Os que apoiam, argumentam a favor da necessidade de uma orientação curricular nacional seja pelo caráter democrático de indicação de conteúdos básicos, que devem ser transmitidos a todos os 
jovens, seja pela diversidade regional de nosso país. Os que recusam, alegam que um currículo deve nascer no seio dos processos culturais no qual as pessoas vivem, e, por conseguinte valorizar as culturas particulares, as diferenças, as diversidades de classe social e gênero, os diferentes discursos e subjetividade. Em função dessa associação entre currículo e diferenças, considera-se que não faz sentido o currículo oficial.

Kaercher (1997, p. 31), por sua vez, afirma que “(..) vistos pela lógica interna do texto, parecem ser extremamente sedutores, pois estão bem escritos e com reflexões sensatas e progressistas. (...)". O autor, portanto, entende que o problema central não é o texto em si, mas sua relação com a realidade da escola pública brasileira. Para ele (p.33):

(...) a questão para a melhoria da qualidade da escola pública brasileira não se fará via PCN's - o problema não é de "conteúdo", de currículo - e nem tampouco da simples compra de milhares de computadores ou parabólicas. As soluções para a precária qualidade de nossas escolas, infelizmente, não são rápidas nem baratas. Não se trata de um problema tecnológico (...), mas sim de uma secular política de descaso com a escola pública. (...)

Essas são algumas das críticas e posicionamentos referentes aos PCN de Geografia para o Ensino Fundamental. Apesar das críticas, percebemos que os PCN têm sido apontados como referência para a elaboração de planejamentos nas escolas e mesmo para realização de avaliações do sistema escolar.

Diante disso, consideramos importante a reflexão sobre os desdobramentos ou conseqüências dos $\mathrm{PCN}$ em relação à prática da Geografia escolar. Neste caso, procuraremos, na seqüência, levantar algumas questões para pensarmos como tem sido a relação dos professores com esse referencial curricular.

\section{Os professores de Geografia e os PCN}

A partir do exposto, podemos perceber que existiu e existe um amplo debate sobre a função, características, conteúdos, referenciais teóricometodológicos e interesses dos PCN. Deve-se ressaltar que esse debate foi conduzido majoritariamente por professores/geógrafos ligados ao ensino 
superior, ou seja, pesquisadores das universidades brasileiras que de uma forma ou outra possuem envolvimento com o ensino de Geografia.

Sendo assim, os termos em que esse debate foi colocado e conduzido relacionam-se às preocupações e anseios dos acadêmicos, em grande parte. Não queremos com isso dizer que a contribuição destes não é relevante, ao contrário, na condição de pesquisadores e formadores de professores cabia a eles este papel.

A grande questão, neste caso, é compreender como os professores do Ensino Fundamental receberam, inseriram-se e posicionaram-se nesse debate. Em outras palavras, seria pensarmos "onde e como fica o professor em meio a esse debate"?

Ainda são poucas as pesquisas e dados que dispomos para fundamentar essa idéia, no entanto, temos a impressão de que grande parte dos professores do Ensino Fundamental passou ao lado desta discussão ou não se inseriram de fato nela, havendo em alguns casos um grande distanciamento em relação às questões que envolvem os PCN.

Vieira (2006) constatou, com base em investigação junto aos professores de Geografia das escolas estaduais de Marília (SP), que as discussões sobre as categorias centrais dos PCN (lugar, paisagem, território e região) não acompanham o teor e profundidade demandada a partir do texto do referido documento o qual possui grande relação com as atuais discussões acadêmicas sobre as mesmas.

Apesar de a autora tecer um conjunto de críticas ao texto dos PCN amparada por autores como Oliveira (1999) que discutimos na seção anterior, ela procurou investigar o conteúdo veiculado pelo documento acerca do significado das categorias lugar, paisagem, território e região analisando a compreensão dos professores sobre estas. Em seu entendimento:

As últimas inovações teórico-metodológicas pretendidas para o ensino de Geografia foram introduzidas oficialmente, em meados da década de 1990, a partir da elaboração e implantação dos Parâmetros Curriculares Nacionais para o ensino de Geografia. Essas inovações se referem à necessidade de incorporação ao ensino das reflexões realizadas na academia a respeito do significado das categorias de lugar, paisagem, território e região. (Vieira, 2006, p. 183) 
A princípio, a autora também entendia que “(...) esse referencial curricular encontra-se disponível em todas as escolas e que constitui um instrumento de atualização e de formação para o professor (...)" (VIEIRA, 2006, p. 54.)

No entanto, os dados obtidos por Vieira mostraram que $60 \%$ dos professores entrevistados admitiram nunca ter tido contato com o conteúdo dos PCN. Dos $40 \%$ restantes, somente $10 \%$ afirmaram ter realizado uma leitura integral do documento. Os demais, afirmaram ter lido parcialmente o seu conteúdo no momento da elaboração do plano anual de ensino, a partir da leitura de pequenos trechos ou do rol de conteúdos programáticos sugeridos.

Mesmo considerando que o número de professores entrevistados (51) é reduzido em relação à quantidade de professores de Geografia no Brasil como um todo, os dados obtidos são significativos enquanto indicativos do que pode ser uma realidade em grande parte das redes de ensino no país.

A pesquisa realizada por Rocha (2007) junto aos professores de Geografia da rede estadual de Dourados (MS) também aponta dados semelhantes em relação ao conhecimento dos professores quanto aos PCN. Apenas $20 \%$ dos entrevistados ${ }^{4}$ afirmaram possuir um bom conhecimento em termos de leitura e entendimento das proposições contidas nos PCN. Os demais consideram seu conhecimento como "médio ou regular".

Neste sentido, é no mínimo preocupante pensarmos que grande parte dos professores do Ensino Fundamental sequer teve contato com o conteúdo do texto dos PCN visto que, independente de suas qualidades, esta é a proposta curricular oficial presente nas escolas do país. Mesmo no caso daqueles que tiveram contato, o nível de conhecimento e reflexão quanto ao conteúdo e proposições do documento não se caracterizou de maneira mais verticalizada.

O que pensarmos, então, quanto ao conhecimento dos professores sobre as críticas e debates ocorridos sobre o documento? Provavelmente, grande parte desses professores também desconhece os termos em que o debate ocorreu e, portanto, não se inseriram nele.

\footnotetext{
${ }^{4} \mathrm{O}$ autor entrevistou 20 professores de Geografia dos 26 atuantes na rede estadual de Dourados (MS) no ano de 2007.
} 
Os dados obtidos por Vieira também mostraram que parte significativa dos professores fez uma leitura parcial de trechos do documento ou do rol de conteúdos programáticos sugeridos visando a elaboração dos planos anuais de ensino. A partir disso, podemos inferir que os PCN têm sido vistos e utilizados como mera listagem de conteúdos/temas a serem trabalhados não havendo qualquer preocupação com a discussão conceitual inerente à proposta.

Pensando nesta direção, ou seja, quanto às formas de utilização dos PCN, Rocha (2007) aponta que 55\% dos professores entrevistados afirmaram terem mudado sua prática após a introdução dos PCN. No entanto, quando perguntados sobre quais seriam essas mudanças, as respostas giraram em torno da "introdução de técnicas que levam os alunos a explicar, compreender e representar os processos de construção dos diversos tipos de paisagens; do trabalho com os temas transversais e através de projetos integrados."

Percebe-se, portanto, que as mudanças introduzidas por esses professores a partir dos PCN estão mais relacionadas às questões de ordem metodológica. Por outro lado, é bastante significativo o percentual de professores que afirmaram não haver mudado suas práticas após a introdução dos PCN (45\%).

Ao discutir a formação continuada dos professores entrevistados, Vieira (2006, p. 142) constatou que o envolvimento do professor de Geografia com o que se produz na academia acerca do conhecimento geográfico também é restrito. Desta forma, "o contato do professor com o conhecimento geográfico, tem sido, em sua maioria, através dos livros didáticos. Mesmo os professores que disseram ter lido autores acadêmicos demonstraram que essa leitura foi através de textos presentes em livros didáticos." (VIEIRA, 2006, p. 142)

Tal constatação nos conduz a pensar que se o livro didático constitui um instrumento de atualização do professor, também, de certa forma, continua sendo o principal referencial do processo de ensino-aprendizagem da Geografia. Neste sentido, em relação aos PCN pode ser que esteja havendo uma mera adequação dos conteúdos do livro didático ao rol de conteúdos sugeridos pelos PCN. 
Sendo assim, os possíveis "avanços" 5 trazidos pelos PCN no tocante à suas proposições conceituais não são efetivados, pois a proposta pode estar sendo utilizada no sentido mais restrito de currículo, ou seja, como mera listagem de conteúdos, desconectados de qualquer referencial conceitual e teórico-metodológico.

A partir de sua pesquisa, Vieira (2006, p. 183) conclui que “(...) as inovações introduzidas oficialmente no currículo da Geografia escolar não se concretizaram na prática da maioria dos professores. (...)"

Os dados e reflexões realizadas por Rocha (2007) também apontam que as mudanças introduzidas na prática dos professores de Geografia da rede estadual de Dourados (MS) após os PCN estão mais relacionadas a procedimentos de ordem metodológica (alguns professores falaram em "técnicas e estratégias pedagógicas") do que teórico-conceitual.

Resta-nos, então, indagar e levantar possíveis caminhos para diminuir este distanciamento ou não concretização das inovações propostas pelos PCN na prática da Geografia escolar. Na seqüência, procuraremos refletir sobre esta questão.

\section{Professor e proposta curricular: em busca da construção de uma relação}

A partir das reflexões realizadas na seção anterior, pudemos constatar que, apesar de já ter se passado uma década que as inovações curriculares foram introduzidas oficialmente entre os professores do Ensino Fundamental, ainda há um grande distanciamento entre professores e PCN.

Nosso intuito neste momento é apontar algumas questões que possam contribuir para a construção de uma relação mais efetiva entre professores e propostas curriculares. Não temos a intenção de fornecer "receitas" de como estabelecer esta relação, mas parâmetros a partir dos quais ela possa ser melhor construída.

Um elemento que acreditamos ser central na construção desta relação é a própria concepção de proposta curricular. É urgente que o sentido de

\footnotetext{
${ }^{5}$ Esta afirmação baseia-se nas idéias de Zanatta (2005) que ao comparar os PCN com propostas curriculares não oficiais, destaca que: "Em que pesem as diferenças no conjunto do pensamento dos autores das propostas acima mencionadas, há entre eles uma preocupação comum no sentido de ampliar a discussão sobre o ensino de Geografia para além da simples definição de conteúdos. (...)"
} 
proposta curricular seja ampliado na concepção dos professores do ensino básico.

Diante do conjunto de discussões que têm se desenvolvido nas últimas décadas sobre conteúdos e objetivos do ensino de Geografia (PEREIRA, 1995; SANTOS, 1995) e mesmo sobre propostas de ensino (CAVALCANTI, 1999; CALLAI, 1998; KAERCHER, 1998, entre outros) não é possível que continue vigente entre a maioria dos professores a concepção de proposta curricular como sinônimo de listagem de conteúdos.

Neste sentido, Zanatta (2005, p. 07) ao analisar diferentes propostas curriculares colocadas para a Geografia atualmente, destaca que seus autores alertam para a necessidade de considerar:

- A seleção dos conceitos geográficos básicos para estruturar os conteúdos do ensino;

- A valorização das diferentes dimensões dos conceitos geográficos para a construção de atitudes, ações, valores que norteiam comportamentos sócio-espaciais;

- A Geografia do aluno, ou seja, suas representações sociais como referência do conhecimento geográfico construído na sala de aula;

- O reconhecimento da relevância da dimensão afetiva no processo do conhecimento;

- A articulação dos componentes do processo de ensino, ou seja, objetivos, conteúdos e métodos.

A partir dos elementos destacados por Zanatta (2005) nota-se que atualmente há uma ampliação do sentido de proposta curricular que se baseia em outros pressupostos que não só a estruturação de conteúdos.

Além disso, é preciso que o professor tenha embasamento teóricometodológico suficiente para compreender a proposta curricular do ponto de vista de seus elementos centrais, identificando a concepção de Geografia explícita ou implícita e seus desdobramentos conceituais, conteudísticos e didáticos. 
Se essa compreensão for possível, o professor poderá, inclusive, optar pelo que vai trabalhar e como vai trabalhar. Como afirma Castellar (1999, p. 50): “(...) A tarefa docente consiste em organizar, programar, dar seqüência aos conteúdos, de forma que o aluno possa realizar uma aprendizagem significativa, encaixando novos conhecimentos em sua estrutura cognitiva prévia e evitando, portanto, uma aprendizagem baseada apenas na memorização (...)"

Sendo assim, é necessário que o professor decida os conteúdos, perceba os conceitos que devem ser articulados a eles, saiba adequar à faixa etária e consiga atuar no sentido de uma aprendizagem significativa. Para que isso ocorra, no entanto, é necessário que "(...) o professor tenha uma formação que permita autonomia e reflexão para definir o que será dado e como ocorrerá o processo de aprendizagem do aluno. (...)" (CASTELLAR, 1999, p. 50).

Neste contexto, as propostas curriculares podem ser melhor utilizadas pelos professores, mas devem ser entendidas de forma mais ampla, para além dos conteúdos e, também, como referências para a construção de sua prática e não definidoras absolutas do que deve ser ensinado.

Para isso, no entanto, necessariamente, conforme destacado por Castellar é preciso que o professor tenha autonomia. E essa autonomia relaciona-se com as condições de sua formação.

Em relação à formação dos professores, principalmente a continuada, o trabalho de Vieira (2006) aponta que:

(...) No que se refere às ações do professor como agente de sua formação, nós constatamos que existe pouca disponibilidade e iniciativa do professor em buscar seu aprimoramento intelectual, seja através de cursos de pós-graduação, de extensão, de atualização ou através da participação em eventos científicos da área em que atua. (...) Poucos são aqueles que têm consciência do seu papel como agente de sua própria formação.(...)

Claro que a autora não ignora as condições concretas em que os professores trabalham, no entanto, salienta que “(...) de nada adianta a concretização de projetos de formação continuada sem um efetivo envolvimento e comprometimento do professor com o processo. (...)" (VIEIRA, 2006, p. 186) 
A questão da formação continuada dos professores foge aos objetivos deste texto, no entanto, destacamos as constatações de Vieira (2006) no sentido de chamar a atenção para a importância da formação, seja ela inicial ou continuada no processo de construção da autonomia do professor.

Essa autonomia, como procuramos salientar, é essencial para a construção de uma relação mais efetiva e qualificada entre professores e propostas curriculares, no caso em questão, os PCN.

\section{Considerações Finais}

Neste texto, procuramos refletir sobre as relações entre professores e Parâmetros Curriculares Nacionais (PCN) para o ensino de Geografia. Partimos da contextualização mais ampla dos PCN em relação à política educacional em que se inserem e destacamos as principais críticas surgidas quanto ao conteúdo do documento.

Na seqüência, levantamos algumas questões e discutimos sobre um possível distanciamento existente entre os professores e essa proposta curricular. Embora dispondo de poucas pesquisas e dados para fundamentar essa idéia, acreditamos que grande parte dos professores do Ensino Fundamental desconhece e não inseriram no debate sobre os PCN.

A partir disso, tentamos indagar e levantar possíveis caminhos para diminuir este distanciamento ou não concretização das inovações propostas pelos PCN na prática da Geografia escolar.

Em nosso entendimento, é necessário que o sentido de proposta curricular seja ampliado na concepção dos professores do ensino básico. Não é possível que continue vigente entre a maioria dos professores a concepção de proposta curricular como sinônimo de listagem de conteúdos, técnicas e estratégias de ensino.

Além disso, é preciso que o professor tenha embasamento teóricometodológico suficiente para compreender a proposta curricular do ponto de vista de seus elementos centrais, identificando a concepção de Geografia explícita ou implícita e seus desdobramentos conceituais, conteudísticos e didáticos. 
Para isso, no entanto, é necessário que o processo de formação do professor forneça condições que permitam a construção de sua autonomia para decidir e optar pelos caminhos a serem seguidos.

Acreditamos que as propostas curriculares e, neste caso, os PCN podem ser melhor utilizados pelos professores, mas devem ser entendidas de forma mais ampla, para além dos conteúdos e, também, como referências para a construção de sua prática e não definidoras absolutas do que deve ser ensinado.

\section{Referências Bibliográficas}

BRASIL. SECRETARIA DA EDUCAÇÃO FUNDAMENTAL. Parâmetros Curriculares Nacionais $-3^{\circ}$ e $4^{\circ}$ ciclos do ensino fundamental. Geografia. Brasília: MEC/SEF, 1998.

CALLAI, Helena C. O ensino de Geografia: recortes espaciais para análise. In: CASTROGIOVANNI, Antônio C. et. al. (Orgs.) Geografia em sala de aula: práticas e reflexões. Porto Alegre: Ed. da UFRS/AGB - Porto Alegre, 1999.

CASTELLAR, Sonia M. V, A formação de professores e o ensino de Geografia. Terra Livre, São Paulo, n. 14, p. 48-55, 1999.

CAVALCANTI, Lana de S. Propostas curriculares de Geografia no ensino: algumas referências de análise. Terra Livre, São Paulo, n. 14, p. 111-128, 1999.

FERRAZ, Cláudio B. O. Reforma Universitária no contexto das reformas do Estado brasileiro.Tempos Históricos, vol. 4, n. 1, Cascavel, p. 207-237, 2002.

GENTILI, Pablo. Adeus à escola pública. A desordem neoliberal, a violência do mercado e o destino da educação das maiorias. In: Pedagogia da Exclusão: crítica ao neoliberalismo em educação. Petrópolis: Vozes, 2000, p. 228-252.

KAERCHER, Nestor A. PCN's: futebolistas e padres se encontram num Brasil que não conhecemos. Terra Livre, São Paulo, n. 13, p. 30-41, 1997.

A Geografia é o nosso dia-a-dia. In: CASTROGIOVANNI, Antônio C. et al. (Orgs.) Geografia em sala de aula: práticas e reflexões. Porto Alegre: Ed. da UFRS/AGB - Porto Alegre, 1999. 
LEHER, Roberto. Reforma universitária do governo Lula: notas para a crítica do documento elaborado pelo GT Interministerial (GTI) - Decreto 20/10/03. Folha de São Paulo, 04 de fevereiro de 2004.

OLIVEIRA, Ariovaldo U. de. Geografia e ensino: parâmetros curriculares em discussão. In: CARLOS, Ana F. A.; OLIVEIRA, Ariovaldo U. de (Orgs.) Reformas no mundo da Educação: parâmetros curriculares e geografia. São Paulo: Contexto, 1999, p. 43-67.

PEREIRA, Diamantino A. C. Geografia escolar: conteúdos e/ou objetivos? Caderno Prudentino de Geografia. Pres. Prudente, n. 17, p. 62-74, 1995.

ROCHA, Emílio. Os PCN's de Geografia do ensino fundamental: Uma análise a partir da visão dos professores da rede estadual de Dourados (MS). 2007. 40 p. Trabalho de Conclusão de Curso (Licenciatura em Geografia). Faculdade de Ciências Humanas, Universidade Federal da Grande Dourados, Dourados.

SANTOS, Douglas. Conteúdo de objetivo pedagógico no ensino da Geografia. Caderno Prudentino de Geografia. Pres. Prudente, n. 17, p. 20-60, 1995.

SILVA JUNIOR, João dos R.; SGUISSARDI, Valdemar. Reforma do Estado e Reforma da Educação Superior no Brasil. In: SGUISSARDI, Valdemar (Org.) Avaliação Universitária em questão: reformas do Estado e da educação superior. Campinas: Autores Associados, 1997, p. 07-39.

SPOSITO, Maria E. B. Parâmetros Curriculares Nacionais para o ensino de Geografia: pontos e contrapontos para uma análise. In: CARLOS, Ana F. A.; OLIVEIRA, Ariovaldo U. de (Orgs.) Reformas no mundo da Educação: parâmetros curriculares e geografia. São Paulo: Contexto, 1999, p. 19-35.

VIEIRA, Noêmia R. As questões das Geografias do ensino superior e do ensino fundamental a partir da formação continuada do professor e das categorias lugar, paisagem, território e região: um estudo da Diretoria Regional de Ensino de Marília. 2006. 200 p. Tese (Doutorado em Geografia). Faculdade de Ciências e Tecnologia, Universidade Estadual Paulista (UNESP) - Campus de Presidente Prudente, Presidente Prudente.

ZANATTA, Beatriz A. As práticas de ensino na escola e as propostas de ensino de geografia. In: 8o ENCONTRO NACIONAL DE PRÁTICA DE ENSINO DE GEOGRAFIA, 2005, Dourados: UFMS, 2005, p. 01-17. 